1 Diabetes Research Centre, Leicester General Hospital, University of Leicester, Leicester, UK

2 London School of Economics and Political Science, London, UK

3 , London, UK

Correspondence to: K Khunti

Cite this as: BMJ2020;369:m2503 http://dx.doi.org/10.1136/bmj.m2503 Published: 23 June 2020

\title{
Covid-19 and ethnic minorities: an urgent agenda for overdue action
}

\author{
The government's report falls seriously short on commitment \\ Kamlesh Khunti, ${ }^{1}$ Lucinda Platt, ${ }^{2}$ Ash Routen, ${ }^{1}$ Kamran Abbasi ${ }^{3}$
}

Demands to address the health inequalities facing ethnic minorities date back at least two decades. Yet it has taken a global pandemic for those demands to be taken seriously. The question now is what can be done and how quickly?

Public Health England's (PHE) initial review on disparities in covid-19 was expected to tackle ethnic inequalities head on; instead the review dedicated just one short section to these concerns. ${ }^{1}$ The review's brief findings on ethnic disparities were stark but consistent with other research, ${ }^{2-4}$ and did not list further actions. The government is believed to have delayed publication of the initial review and suppressed the release of PHE's full report on ethnic minorities. ${ }^{5}$ Kemi Badenoch, England's minister for equalities, first told parliament that PHE could not make recommendations. Following a public outcry, the government has now released the full report, which includes a stakeholder consultation, a rapid review, and a brief set of recommendations. ${ }^{7}$ Given the current intensity of concern over the differential impacts of covid-19, it was insensitive and illogical to delay a report that is largely uncontroversial and limited in its recommendations, albeit broad in its scope.

PHE approached over 4000 external stakeholders, many of whom are seldom heard. Their opinions largely mirror the findings of the rapid review but provide invaluable context and insights into the possible causes of covid-19 disparities. The report is clear that there is a problem. Deaths from covid-19 among people from ethnic minorities are two to four times higher than in the white majority population. The rapid review and the stakeholder consultation suggest that these differences may be partly explained by comorbidities, overcrowded housing, income inequality, and occupational risk, although no original or secondary data are presented to provide a definitive answer. Racism and distrust, says the report, result in limiting access to healthcare. Differential survival by ethnic group, with Bangladeshi men most at risk, is consistent with the established literature on the contribution of comorbidities such as diabetes and on the influence of delayed access to healthcare. The themes of delayed access and the role of racism emerge strongly from stakeholder interviews.

PHE's resulting recommendations are sensible and largely uncontroversial (box 1), but they are not new and fail to direct a clear programme of action. ${ }^{89}$ The proposals lack detail and provide no time frames for delivery or methods of implementation. Crucially, nobody is held responsible or accountable. The report does not say which systems and structures will enable the actions to be delivered. Successful implementation of necessary measures to improve outcomes for ethnic minorities during this pandemic is a distant and receding prospect.

Box 1: Public Health England's core recommendations

- Mandate ethnicity data collection and recording

- Support community participatory research

- Improve healthcare access, experience, and outcome

- Accelerate culturally tailored occupational risk assessment

- Fund and implement culturally tailored covid-19 messaging

- Accelerate culturally tailored chronic disease efforts

- Ensure covid-19 recovery reduces inequality caused by wider health determinants

PHE and others previously identified that wider socioeconomic inequalities and deprivation underpin ethnic disparities in covid-19 outcomes. ${ }^{27}$ Inequalities were exacerbated in recent years by changes to the labour market, ${ }^{10}$ social security system, ${ }^{11}$ and immigration policy. ${ }^{12}$ Low quality or insecure work appears to increase exposure and risks from covid-19. ${ }^{13}$ It is therefore disappointing to see only one recommendation on these deeply rooted wider determinants of health.

The recommendations are silent on the critical issues of employment security, adequate safety nets, and the causes of occupational segregation. Similarly, nothing is said about a longstanding need to reduce household overcrowding, a key candidate for covid-19 transmission. ${ }^{14}$ Social housing restrictions on local authorities impair adequate housing provision for larger and multigenerational households. Interaction between immigration policy and the health risks for ethnic minorities, whether through avoiding seeking care or being unable to take leave from work, is another area that requires sharper focus.

\section{Five actions}

We urge the government to take five immediate steps. Firstly, mandatory collection of ethnicity data must be prioritised, and the new NHS Race and Health Observatory can be a catalyst. ${ }^{15}$ Comprehensive data collection across multiple administrative sources, including death records, will be the foundation for further research into explanatory factors for covid-19 disparities. For example, a better understanding of intrahousehold transmission will have implications for the causal role of larger and multigenerational households. Disaggregating ethnic groups is vital since exposure, survival, and risk factors vary by group. Comorbidities are more influential in Bangladeshi men, and overcrowding is more likely 
in Bangladeshi households. Black Africans, who face the highest age adjusted death rates, are more likely to work in the social care sector than their white majority peers. ${ }^{2}$

Secondly, culturally tailored occupational risk assessment for covid-19 is urgently required and should be delivered with clear messaging. Thirdly, priority covid-19 testing for all public facing jobs, already implemented by some NHS trusts, ${ }^{16}$ should become standard practice. Fourthly, explicit ownership of the recommendations and accountability for their implementation at ministerial level is essential to achieve the level of detailed thought and action needed to reduce the dangers that covid-19 poses to ethnic minority populations. Fifthly, the government and public health organisations must make an open and tangible commitment to working together to end health inequalities for ethnic minorities.

The current ethnic and socioeconomic disparities in covid-19 cannot be separated from social determinants of health, particularly deprivation, and widening health inequalities. ${ }^{17}$ Covid-19 does discriminate on the basis of inequalities, and the government can no longer distance itself from its responsibilities to the ethnic minority population and workforce.

Competing interests: We have read and understood BMJ policy on declaration of interests and declare the following interests: KK is director of the Centre for Black Minority Health, University of Leicester, is a trustee of the charity South Asian Health Foundation, and co-chair of its diabetes working group. KK is member of Independent SAGE. KA is a patron of the South Asian Health Foundation. The BMJ was involved with and supported the creation of the NHS Race and Health Observatory.

1 Public Health England. Disparities in the risk and outcomes of COVID-19.2020. https://assets.publishing.service.gov.uk/government/uploads/system/uploads/attachment_data/file/892085/disparities_review.pdf

2 Platt L, Warwick P. Are some ethnic groups more vulnerable to COVID-19 than others? Institute for Fiscal Studies, 2020

3 Williamson E, Walker AJ, Bhaskaran KJ, et al. OpenSAFELY: factors associated with COVID-19-related hospital death in the linked electronic health records of 17 million adult NHS patients. medRxiv 2020.05.06.20092999 [Preprint.] https://www.medrxiv.org/content/10.1101/2020.05.06.20092999v1).

4 Office for National Statistics. Coronavirus COVID-19 related deaths by ethnic group, England and Wales: 2 March 2020 to 10 April 2020. (https://www.ons.gov.uk/peoplepopulationandcommunity/birthsdeathsandmarriages/deaths/articles/coronavirusrelateddeathsbyethnicgroupenglandandwales/2march2020to10april2020

5 Bhopal R. Delaying part of PHE's report on covid-19 and ethnic minorities turned a potential triumph turned into a PR disaster. BMJ Opinion 16 Jun 2020.

https://blogs.bmi.com/bmi/2020/06/16/delaying-part-of-phes-report-on-covid-19-and-ethnicminorities-turned-a-potential-triumph-turned-into-a-pr-disaster/?utm_source=feedburner\&utm_medium=feed\&utm_campaign=Feed\%3A+bmj\%2Fblogs+\%28Latest+BMJ+blogs\%29\&g=w_bmj-com.

6 lacobucci G. Covid-19: review of ethnic disparities is labelled "whitewash" for lack of recommendations. BMJ2020;369:m2208. doi: 10.1136/bmj.m2208 pmid: 32493696

7 Public Health England. Beyond the data: understanding the impact of COVID-19 on BAME groups. 2020. https:/assets.publishing.service.gov.uk/government/uploads/system/uploads/attachment_data/file/892376/COVID_stakeholder_engagement_synthesis_beyond_the_data.pdf

8 Boote J, Wong R, Booth A. "Talking the talk or walking the walk?" A bibliometric review of the literature on public involvement in health research published between 1995 and 2009. Health Expect 2015;18:44-57. doi: 10.1111/hex.12007 pmid: 23033933

9 King's Fund. Access to health care and minority ethnic groups. King's Fund, 2006.

10 Goos M, Manning A. Mcjobs and Macjobs: the growing polarisation of jobs in the UK. In: Dickens R, Gregg P, Wadsworth J, eds. The labour market under New Labour. Palgrave Macmillan, 2003:70-85doi: 10.1057/9780230598454_6.

11 Special Rapporteur on Extreme Poverty and Human Rights. Report on visit to the United Kingdom of Great Britain and Northern Ireland. 2019. https://undocs.org/A/HRC/41/39/Add.1

12 Williams W. Windrush lessons learned review. 2020. https://www.gov.uk/government/publications/windrush-lessons-learned-review

13 ONS. Coronavirus (COVID-19) related deaths by occupation, England and Wales: deaths registered up to and including 20 April 2020. (https://www.ons.gov.uk/releases/covid19relateddeathsbyoccupationenglandandwalesdeathsregistereduptoandincluding20thapril2020).

14 Raisi-Estabragh Z, McCracken C, Bethell MS, etal. Greater risk of severe COVID-19 in Black, Asian and Minority Ethnic populations is not explained by cardiometabolic, socioeconomic or behavioural factors, or by $25(\mathrm{OH})$-vitamin D status: study of 1326 cases from the UK Biobank. J Public Health (Oxf) 2020;•••.. doi: 10.1093/pubmed/fdaa095. pmid: 32556213

15 Rao M. The NHS race and health observatory-its time has come. BMJ Opinion 17 Jun 2020. https://blogs.bmj.com/bmj/2020/06/17/the-nhs-race-and-health-observatory-its-time-has-come
16 Second trust recognises BAME staff as "vulnerable and at risk." Pulse2020 http://www.pulsetoday.co.uk/clinical/clinical-specialties/respiratory-/second-trust-recognises-bame-staff-as-vulnerable-and-at-risk/20040710.article.

17 Marmot M, Allen J, Boyce T, Goldblatt P, Morrison J. Health equity in England: the Marmot review 10 years on. Institute of Health Equity, 2020.

This article is made freely available for use in accordance with BMJ's website terms and conditions for the duration of the covid-19 pandemic or until otherwise determined by BMJ. You may use, download and print the article for any lawful, non-commercial purpose (including text and data mining) provided that all copyright notices and trade marks are retained. 